\title{
Modeling Biodegradation and Reactive Transport: Analytical and Numerical Models
}

Y. Sun, L. Glascoe

June 14, 2005

Innovative Approaches for the Remediation of Subsurface-Contaminated Hazardous Waste Sites: Bridging Flask and Field Scales (American Chemical Society Publication) 
This document was prepared as an account of work sponsored by an agency of the United States Government. Neither the United States Government nor the University of California nor any of their employees, makes any warranty, express or implied, or assumes any legal liability or responsibility for the accuracy, completeness, or usefulness of any information, apparatus, product, or process disclosed, or represents that its use would not infringe privately owned rights. Reference herein to any specific commercial product, process, or service by trade name, trademark, manufacturer, or otherwise, does not necessarily constitute or imply its endorsement, recommendation, or favoring by the United States Government or the University of California. The views and opinions of authors expressed herein do not necessarily state or reflect those of the United States Government or the University of California, and shall not be used for advertising or product endorsement purposes. 


\title{
Modeling Biodegradation and Reactive Transport: Analytical and Numerical Models
}

\author{
Yunwei Sun and Lee Glascoe* \\ Lawrence Livermore National Laboratory, Livermore, CA 94551
}

The computational modeling of the biodegradation of contaminated groundwater systems accounting for biochemical reactions coupled to contaminant transport is a valuable tool for both the field engineer/planner with limited computational resources and the expert computational researcher less constrained by time and computer power. There exists several analytical and numerical computer models that have been and are being developed to cover the practical needs put forth by users to fulfill this spectrum of computational demands. Generally, analytical models provide rapid and convenient screening tools running on very limited computational power, while numerical models can provide more detailed information with consequent requirements of greater computational time and effort. While these analytical and numerical computer models can provide accurate and adequate information to produce defensible remediation strategies, decisions based on inadequate modeling output or on over-analysis can have costly and risky consequences. In this chapter we consider both analytical and numerical modeling approaches to biodegradation and reactive transport. Both approaches are discussed and analyzed in terms of achieving bioremediation goals, recognizing that there is always a tradeoff between computational cost and the resolution of simulated systems.

\section{Introduction}

It has long been recognized that quantitative tools are necessary for the assessment and management of natural attenuation and bioremediation (for 
example, see (1)). Typically, mathematical models are used to determine the development of subsurface contaminant plumes and to evaluate the effectiveness of different bioremediation strategies. A wide range of numerical and analytical computer codes is currently available (2), which can be used to solve those biodegradation and reactive transport mathematical models. To appropriately select and apply computer codes, it is necessary to understand (a) the modeled physical system, (b) the modeling scope, (c) the computer code assumptions and limitations, and (d) the tradeoff between modeling resolution and computational cost.

Reactive bioattenuation examples include processes such as radionuclide decay, denitrification, biodegradation of chlorinated solvents, etc. Consider the anaerobic degradation of the most frequently detected organic compounds in groundwater, perchloroethylene (PCE) and trichloroethylene (TCE) (3); the reaction pathway of PCE and TCE biodegradation is shown in Figure $1(4,5)$. PCE reacts to produce TCE; TCE reacts to produce three daughter species, cis1,2-dichloroethylene (cis-1,2-DCE), trans-1,2-dichloroethylene (trans-1,2DCE), and 1,1-dichloroethylene (1,1-DCE) simultaneously; the three daughter species further react to produce vinyl chloride (VC); and $\mathrm{VC}$ reacts to produce ethylene (ETH) $(3,4)$.

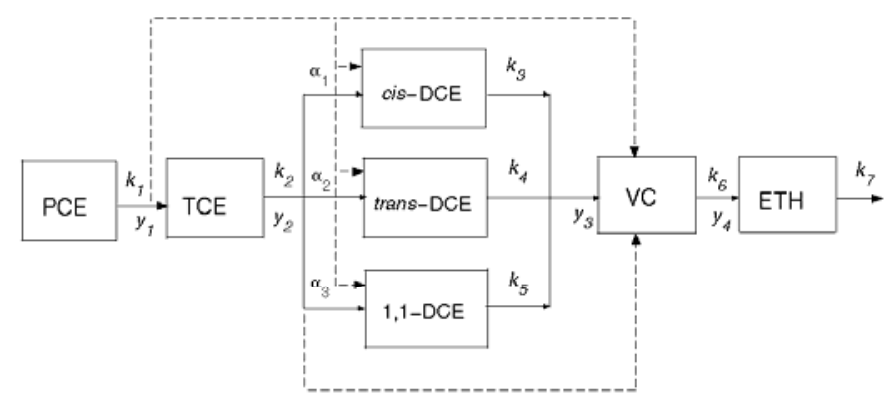

Figure1. PCE and TCE degradation pathway. $k_{i}, \forall i=1,2, \cdots, 7$ are the first-order reaction rates; $y_{i}, \forall=1,2,3,4$ are yield coefficients; and $\alpha_{1}, \alpha_{2}, \alpha_{3}$ are product distribution factors of the reduction of trichloroethylene (TCE). Dashed lines represent other possible reaction ways. 
In order to simulate the transport phenomena with the coupled PCE/TCE reaction network, the general mass balance equations need to be solved (6):

$$
\frac{\partial c_{i}}{\partial t}=-\nabla \cdot\left(\mathbf{v}_{i} c_{i}-\nabla \cdot \mathbf{D}_{i} c_{i}\right)+\frac{q_{i}^{s} c_{i}^{s}}{\phi}+f_{i}(\mathbf{c}), \quad \forall i=1,2, \cdots, n
$$

where $c_{i}\left[\mathrm{M} \mathrm{L}^{-3}\right]$ is the concentration of $i$ th species; $t$ is time $[\mathrm{T}] ; \mathbf{v}\left[\mathrm{LT}^{-1}\right]$ is the vector of velocity; $\mathbf{D}\left[\mathrm{L}^{2} \mathrm{~T}^{-1}\right]$ is the tensor of dispersion coefficients; $n$ is the total number of species; $q^{s}$ and $c^{s}$ are the source/sink quantity and concentration; $f$ is the gain or loss due to reactions. The source/sink term can also be written as boundary conditions. Eq 1 can be solved either analytically or numerically based on the complexity of the modeled systems. The discussion below focuses on how the modeling of complex reactive systems, such as PCE and TCE degradation, would be approached for both analytical and numerical solutions.

\section{Analytical Modeling of Biodegradation and Reactive Transport}

\section{Scope of Analytical Models}

After constructing an appropriate mathematical model in terms of relevant state variables for problems of interest, the model must be solved either directly through analytical means or by employing numerical methods. For the sake of speed and efficiency, the preferred method to solve the model is an analytical solution; however, most problems of practical interest introduce complexities, such as irregular shapes of domain-boundaries, heterogeneities, non-linearities, and irregular source functions, which constrain the derivation of an analytic solution. For this reason, numerical methods are employed to solve the mathematical model increasing computational effort that increases with modeling resolution.

The use of numerical and analytical solutions should be viewed as mutually complementary. Sometimes, the complexity of contaminant systems may require the use of numerical models to represent, for example, a special geometry, heterogeneity, or distributed physical and chemical properties. However, computational complexity resulting from the implementation of physically and geometrically intricate aspects of a simulation model results in increased algorithm detail and a more involved algorithm execution. In addition to increased simulation demands, higher labor costs for model development and maintenance, and data collection requirements are important concerns, especially for numerical models. Because of the advantages of analytical solutions, (including efficiency, speed and ease-of-use) it is often preferable to simplify a given flow and transport problem to the extent that an analytical solution can be obtained. 
Often rapid analytical solutions are used to facilitate confident decisionmaking, and numerical solutions are applied at more advanced stages of bioremediation problem at higher resolution levels. Also, analytical models are required for the verification of the development of numerical codes, which may solve very complex problems. When deciding between the tradeoffs of model resolution and computational effort and, therefore, between the employment of an analytical model as opposed to a numerical model, one should consider the five reasons to use analytical solutions outlined by Javandel et al. (7 ):

- Where applicable, analytical methods are the most economical approach.

- Analytical methods are probably the most efficient alternative when data necessary for identification of the system are sparse and uncertain.

- Analytical methods are always the most useful means for an initial estimation of the order of magnitude of contaminant extent.

- Analytical models do not require experienced modelers or complex numerical codes.

- Analytical models, in many cases, provide a rough estimate that can be obtained through published tables. When application of simple computer codes for evaluation of analytical solutions is needed, the input data are usually very simple and do not require a detailed familiarity with the codes.

Discussed in the subsections below are specific examples of how reactive transport can be represented and solved analytically. Note that while we are not limiting ourselves in this discussion to a one-dimensional description, in order to simplify the presentation of the mathematical model, only a one-dimensional case is discussed.

\section{Analytical Models and Solutions}

Analytical solutions of reactive transport are usually developed under relatively simple flow and transport conditions. The differential equations (eq 1) governing species transport with first-order reactions in a groundwater system are described as $(8)$ :

$$
\frac{\partial \mathbf{c}}{\partial t}+L(\mathbf{c})=\mathbf{A c}, \quad L(\mathbf{c})=-D \frac{\partial^{2}}{\partial x^{2}}+v \frac{\partial}{\partial x}
$$

where $\mathbf{c}$ is the vector of concentrations $\left[\mathrm{ML}^{-3}\right] ; D$ is the dispersion coefficient $\left[\mathrm{L}^{2} \mathrm{~T}^{-1}\right] ; v$ is the groundwater velocity $\left[\mathrm{LT}^{-1}\right] ; x$ is the coordinate in the direction of flow [L]; and $\mathbf{A}$ is the first-order reaction matrix. 


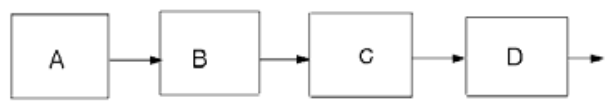

(a)

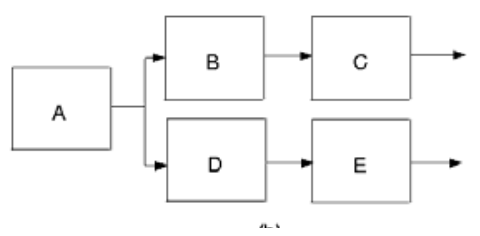

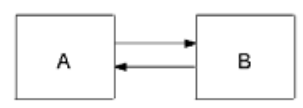

(c)

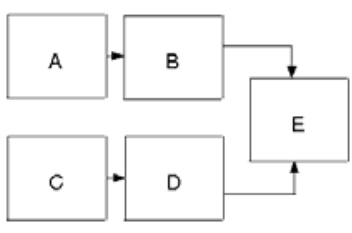

Figure 2. Basic reaction patterns. (a) sequential reactions; (b) parallel reactions; (c) reversible reactions; and (d) convergent reactions.

If vector $\mathbf{c}$ becomes a scalar variable $c$, eq 2 represents the transport system of a single species. The reaction matrix is determined by the reaction networks (or biodegradation pathways), which can be sequential, parallel, reversible, or convergent as illustrated in Figure 2.

To best review the capabilities along with the necessary assumptions and limitations of modeling reactive transport using analytical solutions, we discuss three topical modeling examples: single species transport, multiple species transport, and reactive transport in fractured rock.

\section{Single Species Transport}

Ogata (9) and Bear (10) were the first to derive analytical solutions to contaminant transport equations for one-dimensional problems. Ogata's solution covers advection and dispersion, while Bear's solution added the first-order reaction for a single contaminant species. Since these pioneering efforts, the development of analytical solutions for contaminant transport problems has become an important part of contaminant hydrology. van Genuchten and Alves (11) and Toride et al. (12) compiled various analytical solutions for solving the one-dimensional solute transport equations. Beljin (13) and Wexler (14) reviewed analytical solute transport models for one-, two-, and threedimensional systems. However, for all of these solutions the fundamental partial differential equations (PDEs) represent the transport of either a nonreactive 
tracer or a single reactive species. Reactions are assumed to be first-order in these solutions and are used primarily to address transport phenomena, rather than biochemical reactions. When these solutions are used to represent contaminant transport, the reaction products from biodegradation cannot be addressed. Therefore, these analytical solutions are of the most limited use when addressing, for example, one of the most challenging aspects of managing chlorinated solvent contaminants: the fact that the degradation daughter products are often more toxic than the parent contaminant (15).

\section{Multiple Species Transport}

Since the 1970s there have been efforts to derive analytical solutions for the reactive transport of multiple species. Cho (16) derived an analytical solution to a three-species chain with a simple boundary condition. Lunn et al. (17) used the Fourier transform method to derive the same solution of three-species chain with first-order reactions. van Genuchten (18) used the Laplace transform method and extended previous analytical solutions to a four-species chain. Because of the complexity of inverse Laplace transforms or other integral transforms, the difficulty of deriving analytical solutions for the transport of multiple sequentially reactive species increases exponentially with the species number. Sometimes, implementation of analytical solutions becomes a tedious process because complicated mathematics is involved, and, perhaps worse, there is a perceived gap between the development of analytical solutions and practical applications.

In order to bridge this perceived "practicality gap" for analytical solutions, Sun et al. (19) derived a linear transform approach, which decomposes a reactive transport system coupled by reaction terms into multiple independent subsystems with easily derived analytical solutions.

The transform is defined as a linear function of species concentrations as (19):

$$
a_{i}=c_{i}+\sum_{j=1}^{i-1}\left[\prod_{l=j}^{i-1} \frac{y_{l} k_{l}}{k_{l}-k_{i}}\right] c_{j}, \quad \forall i=1,2, \cdots, n
$$

where $a_{i}\left[\mathrm{ML}^{-3}\right]$ is the concentration of species $i$ in the transformed domain ("a" domain). Then, the system equation coupled by reaction matrix $\mathbf{A}$ can be simplified as:

$$
\frac{\partial \mathbf{a}}{\partial t}+L(\mathbf{a})=\Lambda \mathbf{a}
$$


where $\Lambda$ is a diagonal matrix of $n \times n$ containing the first-order reaction rates of all species, $k_{i}, i=1,2, \cdots, n$. By employing this transform, each partial differential equation (PDE) in eq 4 becomes independent and may be solved separately. The transform significantly reduces the complexity of the coupled reactive transport system (eq 2) and, hence, analytical solutions can either exist or can be developed. The solution scheme of Sun et al. (19) extended the analytical solution capabilities from four species to an unlimited number of species. However, this method is only limited to serial reaction patterns or the parallel reaction networks that can be further decomposed to serial patterns. Sun et al. (20) extended this work by deriving an analytical solution of first-order decay chain in multiple phases using this transformation.

Clement (21) mathematically proved Sun et al.'s (19) transform and illustrated that singular value decomposition (SVD) can be used to derive analytical solutions of transport with convergent reactions. When SVD is used, analytical solutions become available for convergent and reversible reactions. For instance, if the reaction matrix, $\mathbf{A}$, is a diagonalizable matrix, it can be written as:

$$
\mathbf{A}=\mathbf{S} \boldsymbol{\Lambda} \mathbf{S}^{-1}
$$

where $\boldsymbol{\Lambda}$ is a diagonal matrix containing the eigenvalues of $\mathbf{A}$, and $\mathbf{S}$ is a matrix whose columns are linearly independent eigenvectors of $\mathbf{A}$. For the sequential first-order reactions, $\boldsymbol{\Lambda}$ in eq 5 is exactly the diagonal matrix $\boldsymbol{\Lambda}$ in eq 4. Substituting eq 5 into eq 2 yields

$$
\frac{\partial \mathbf{c}}{\partial t}+L(\mathbf{c})=\mathbf{S} \Lambda \mathbf{S}^{-1} \mathbf{c}
$$

Multiplying by $\mathbf{S}^{-1}$, eq 6 becomes eq 4 where $\mathbf{a}=\mathbf{S}^{-1} \mathbf{c}$.

Each PDE in eq 4 is independent of other PDEs. The analytical solutions of eq 4 , in terms of a, are available for a variety of boundary conditions. Finally, the solution of $\mathbf{c}$ can be derived as $\mathbf{C}=\mathbf{S} \mathbf{a}$.

Clement (21) solved the SVD method numerically for the transform matrices while the solutions were derived semi-analytically. Lu et al. (8) derived a closed-form solution of TCE transport with the convergent reactions using SVD. The analytical solution of Lu et al. (8) demonstrated the significance of considering the convergent reactions. Sun et al. (20) extended Lu et al.'s work and derived analytical solutions for the entire PCE reaction network (Figure 1). 
Note that all of the linear systems discussed above $(19,21,8,20)$ have a fundamental assumption that all represented species share the same retardation factor. Eykholt and Li (22) developed a semi-analytical solution of a linear reaction network with different retardation factors using a response function approach. Since numerical convolution is involved, the method is less transparent, more difficult to employ, and, ultimately, difficult to implement as a screening/planning tool. Bauer et al. (23) developed a Laplace domain solution using a recursive form for a different retardation system. The concentration of a daughter species is expressed as a linear function of ancestor concentrations, and the factor of each species concentration is calculated using the recursive form. Quezada et al. (24) used Laplace transformation and linear transformation to decouple the first-order reactive system with distinct retardation factors. Though both Bauer et al. (23) and Quezada et al. (24) have made significant progress in first-order reactive transport, the complexity of inverse Laplace transforms makes code implementation difficult. When numerical inverse Laplace transforms are involved, the approach becomes even more complicated. Both the Eykholt and Li (22) and the Bauer et al. (23) approaches are based on a unimolar assumption, that is, the stoichiometry of the reaction is such that one mole of product is produced by consuming one mole of reactant.

\section{Reactive Transport in Fractured Rock}

The potential geologic repository for high-level nuclear waste at Yucca Mountain, much of which is comprised of a fractured volcanic tuff, has led to an increased interest in the behavior of radionuclide transport in fractures and in better understanding ground water flow and transport in fractured rock (e.g., 25, 26). Starting from a single or from a few parallel fractures in the rock matrix, several studies have focused on deriving analytical solutions. Tang et al. (27) developed an analytical solution to a mathematical model and investigated the fundamental dynamics of the transport of a single radionuclide along a single fracture. Sudicky and Frind (28) extended this solution to multiple parallel fractures, and, later, they derived an analytical solution for the reactive transport of a two-member decay chain in the single fracture (29). Cormenzana (30) provided a simplified form of the Sudicky and Frind (29) solution. Because of the difficulties involved in inverse Laplace transforms, analytical solutions for transport in fractured systems are limited to one or two species. To avoid the difficulties noted by Sudicky and Frind (29) in extending their approach to multiple species, the transformation of Sun et al. (19) was employed to decompose the partial differential equations, which are coupled by reaction terms into independent subsystems. Then, the solution to single species transport in the single fractured system can be applied to derive solutions to $\mathrm{N}$-member solvable decay chains (31). 


\section{Numerical Modeling of Biodegradation and Reactive Transport}

Analytical and numerical models of biodegradation and reactive transport are always complementary. Compared with analytical solutions, numerical methods provide inexact solutions with fewer simplifying assumptions. Additionally, numerical solutions can be used to simulate transport within complex hydrogeologic systems coupled with multiple reactions for which reaction stoichiometry and networks vary spatially and temporally. The hydrogeologic systems can be heterogeneous and anisotropic, and flow systems can be transient with complex initial and boundary conditions. Numerical methods have been successfully and routinely employed for simulating biodegradation and reactive transport $(32,33,34,35,36,37,2,38,39,40)$.

\section{Operator-split Numerical Approach}

Operator-split strategy is the best practical approach (41) to solve the partial differential equations coupled by reactions, although many other numerical solution schemes exist. In the operator-split approach, the partial-differentialequation system (eq 1) can be split into a few subsystems (Table I): advection, dispersion, source/sink-mixing, and reactions, which are then solved using appropriate approaches $(35,41)$.

Table I. Operator-split Components

\begin{tabular}{ccccc}
\hline PDEs & Advection & Dispersion & $\begin{array}{c}\text { Source/ } \\
\text { Sink-mixing }\end{array}$ & Reactions \\
\hline$\partial c_{i} / \partial t=$ & $-\nabla \cdot \mathbf{v}_{i} c_{i}$ & $\nabla \cdot\left(\nabla \cdot \mathbf{D}_{i} c_{i}\right)$ & $q_{i}^{s} c_{i}^{s} / \phi$ & $f(\mathbf{c})$ \\
& $\forall i=1,2, \cdots, n$ & & \\
\hline
\end{tabular}

In the basic reactive transport equation (eq 1), advection, dispersion, and source/sink-mixing are species-independent. The velocity and dispersion coefficient are normalized by the retardation factor of the species. The first three terms in Table I for each species can be solved without considering other species concentrations. However, the reaction equations are location-independent and are coupled by other species concentrations at the same location. In other words, reaction equations can be solved only by discretizing the time domain.

Much of the difficulty of modeling reactive transport and biodegradation is associated with the representation of the often complicated reaction term, $f(\mathbf{c})$. 
Discussed below are some of the specific issues associated with solving common numerical problems in reactive transport modeling including the modeling of reaction kinetics.

\section{Numerical Modeling of Reaction Kinetics}

The partial differential equations described by eq 1 are coupled by the reaction term, $f(\mathbf{c})$. Depending on the type of system being analyzed, various mathematical forms of reaction kinetics can be used to describe this term (35, 33). For example, depending upon the prevailing environmental conditions, aerobic biodegradation can be described as (a) no reaction, (b) a first-order reaction, (c) an instantaneous reaction, (d) a Monod reaction with constant biomass, or (e) a single or dual Monod reaction coupled to biomass growth.

\section{No Reaction}

Often, it is assumed that subsurface contaminants are stable, i.e., they do not interact with subsurface systems or degrade in any way. In such a case, the reaction term, $f(\mathbf{c})$, is set to zero, and a single-species transport system is used to provide a basis for demonstrating bioremediation.

\section{First-order Reaction}

The first-order reaction is expressed as the increased amount of a contaminant by the decay (degradation) of its parent species and the decreased amount by its decay into the daughter species:

$$
\frac{\partial c_{i}}{\partial t}=k_{i-1} c_{i-1}-k_{i} c_{i}
$$

with the $k_{i}$ canceling for $i=1$ and $i=n$. The analytical solution to the system of eq 7 for batch reactor conditions has been in use for nearly 100 years (42). However, numerical solvers are required when transport is involved, especially when eq 7 becomes "stiff" (described in further detail below).

\section{Instantaneous Reaction}

In many instances the parameters that describe the kinetics of biological reactions are not available, and the aerobic biodegradation process is approximated by an instantaneous reaction (43). The ratio of the amount of oxygen consumed to the amount of contaminant destroyed by the reaction is usually estimated by an appropriate stoichiometric constant, and the change of concentration due to the instantaneous reaction is expressed as:

$$
\Delta c=o / F, o=0, \forall c>o / F \quad \Delta o=c F, c=0, \forall c<o / F
$$


where $c$ and $o$ are the contaminant and oxygen concentrations and $F$ is the ratio of oxygen to contaminant consumed (34).

\section{Reaction with Constant Biomass Concentration}

The double Michaelis-Menten law $(43,44,34,45,46,2,47)$ is often used to describe the kinetics of microbial transformation and nutrient (oxygen) and substrate (contaminant) concentrations. If a dual-substrate Monod expression is used, assuming the biomass concentration is constant everywhere at any time, the nonlinear reaction term can be written for the contaminant and oxygen concentrations as:

$$
f_{c}=X \mu\left(\frac{c}{K_{c}+c}\right)\left(\frac{o}{K_{o}+o}\right), f_{o}=F f_{c}
$$

where $\mu$ is the maximum contaminant utilization rate per unit biomass $\left[\mathrm{T}^{-1}\right] ; X$ is the constant biomass concentration $\left[\mathrm{M} \mathrm{L}^{-3}\right]$; and $K_{c}$ and $K_{o}$ are contaminant and oxygen half saturation constants $\left[\mathrm{M} \mathrm{L}^{-3}\right]$, respectively. Sometimes, a multiple Monod equation is used $(48,37,47,49)$ :

$$
f_{c}=X \mu \prod_{i=1}^{n}\left(\frac{c_{i}}{K_{i}+c_{i}}\right)
$$

\section{Reaction With Biomass Growth}

To fully describe the biodegradation processes, microbial growth and transport must also be considered. The full coupling of Monod kinetics with biomass growth, decay, and attachment/detachment between the liquid and solid phases can be expressed as (33):

$$
\begin{aligned}
& f_{c}=\mu\left(X_{a}+\frac{\rho X_{s}}{\phi}\right)\left(\frac{c}{K_{c}+c}\right)\left(\frac{o}{K_{o}+o}\right), f_{o}=F f_{c} \\
& f_{X_{a}}=\mu y X_{a}\left(\frac{c}{K_{c}+c}\right)\left(\frac{o}{K_{o}+o}\right)-K_{r} X_{a}-K_{a} X_{a}+\frac{K_{d} \rho X_{s}}{\phi} \\
& f_{X_{s}}=\mu y X_{s}\left(\frac{c}{K_{c}+c}\right)\left(\frac{o}{K_{o}+o}\right)-K_{r} X_{s}-K_{d} X_{s}+\frac{K_{a} \phi X_{a}}{\rho}
\end{aligned}
$$

where $X_{a}\left[\mathrm{M} \mathrm{L}^{-3}\right]$ and $X_{s}\left[\mathrm{M} \mathrm{M}^{-1}\right]$ are the aqueous phase and solid phase biomass concentrations, respectively; $y$ is biomass/substrate yield coefficient $\left[\mathrm{M} \mathrm{M}^{-1}\right] ; K_{r}$ is decay rate $\left[\mathrm{T}^{-1}\right] ; K_{a}$ and $K_{d}$ are attachment and detachment coefficients $\left[\mathrm{T}^{-1}\right] ; \rho$ 
is bulk density $\left[\mathrm{M} \mathrm{L}^{-3}\right]$. Note that biomass is exchanged between aqueous phase and solid phase, and the solid phase biomass is often assumed to not be transported by either advection or dispersion.

\section{Coupled Stiff Reactions}

Unlike equilibrium reactions, which can be expressed in a generalized format of stoichiometric matrices, kinetic reactions vary from linear to nonlinear formats and from nonstiff to stiff problems. Often, the formulation of reaction kinetics is site-specific, even varying with time and spatial coordinates. When kinetics reactions are coupled in the partial differential equations for transport, the operator-split strategy is often utilized to develop a general solution scheme. Incorporation of detailed kinetic reactions in a transport system can result in a "stiffness" of governing equations. As a consequence of this equation stiffness, explicit time integration of the reaction source terms is restricted to very small time steps. The system is said to be "stiff" when two species have very different natural time scales. Environmental and geochemical systems are often stiff when equilibrium (fast reactions) and kinetics (slow reactions) are coupled in transport equations. However, fully implicit time integration of reaction source/sink terms together with implicit time schemes of transport equations requires much larger computer memories. It is unnecessary, or at least inefficient, to use stiff ODE (ordinary differential equation) solvers, such as implicit time integration of reaction source/sink terms, to solve non-stiff systems. In order to cover a wide range of possible reactions (fast or slow, stiff or nonstiff) for groundwater biodegradation, it is essential to measure stiffness and select the appropriate solvers. An efficient operator split construction is used in RT3D (35) to solve the coupled transport equation employing the LSODE/LSODI solver (50) for solving the reaction terms.

Kinetics reaction terms in the transport PDEs cannot be explicitly treated as source/sink terms. In order to satisfy the stability condition of ODE solutions, $\Delta t$ for the reaction terms must be very small. In other words, each transport time step needs to be subdivided into many reaction time steps. However, when the ODEs of the reaction terms become stiff, explicit solution schemes will fail. One can get the practical feeling about the stiffness from the following first-order reactions when $k_{1}=10^{6}$ and $k_{2}=10^{-3}$ :

$$
\stackrel{k_{1}}{ } \stackrel{k_{2}}{C_{1}} \stackrel{C_{2}}{\rightarrow}
$$

The reaction terms are expressed as: 


$$
\frac{\partial c_{1}}{\partial t}=-k_{1} c_{1}, \quad \frac{\partial c_{2}}{\partial t}=-k_{1} c_{1}-k_{2} c_{2}
$$

The stability condition requires $\Delta t<10^{-6}$ while the influence of $k_{2} c_{2}$ can only be seen after $10^{3} \sim 10^{9}$ time steps. In this way, the explicit scheme will cause the accumulation of round-off error. Gear (51) developed the first algorithm for such stiff ODEs. One can use MATLAB (52) ODE solvers, ode45 and ode45s for this problem.

When both equilibria and kinetics are coupled in the transport equations, flexible and robust solvers need to be selected for handling the mixed systems of differential and algebraic equations. Clement et al. (35) successfully implemented LSODE (50) into RT3D to cover a wide range of kinetic reactions. However, the current version of RT3D is only limited to kinetic reactions. To include both equilibria and kinetics, it is suggested that both LSODE and LSODI be implemented.

\section{Representative Analytical and Numerical Codes}

\section{Analytical Computer Codes for Biodegradation and Reactive Transport}

Several computer codes have been developed based on analytical solutions of reactive transport. This limited review only considers those frequently used in the environmental remediation industry.

AT123D

AT123D (53) is a three-dimensional analytical solution package for transport and fate. Processes simulated include advection, dispersion, diffusion, adsorption, and biological decay. Contaminant releases can be simulated as instantaneous, continuous or varying loads. Source load configurations can be established as a point, line, plane, or volume release.

\section{BIOSCREEN}

BIOSCREEN is a screening level transport code that simulates the bioremediation and reactive transport of dissolved hydrocarbons or many other contaminants. It is based on the Domenico (54) analytical solution of a single contaminant transport in three dimensions and can simulate advection, dispersion, adsorption (linear equilibrium) and first-order reaction. Groundwater flow is assumed uniform with constant velocity. The reaction options coupled in the contaminant transport include (1) no reaction, (2) first-order decay, and (3) biodegradation based on instantaneous reactions. 


\section{BIOCHLOR}

BIOCHLOR (55) is a screening code that simulates remediation by natural attenuation of dissolved solvents at chlorinated solvent release sites. BIOCHLOR can be used to simulate solute transport without decay and solute transport with biodegradation modeled as a sequential first-order process within one or two different reaction zones. The software, programmed in the Microsoft Excel (Microsoft Corporation, Redmond, WA) spreadsheet environment and based on the Sun et al. (19) transform and the Domenico (54) analytical solution of solute transport model, has the ability to simulate one-dimensional advection, three-dimensional dispersion, linear adsorption, and biotransformation via reductive dechlorination. Reductive dechlorination is assumed to follow a sequential first-order decay process. However, BIOCHLOR is not limited to the biodegradation of chlorinated solvents. It can also be used for simulating radionuclide transport, denitrification, etc. Case studies can be found in (56).

PLUME2D

PLUME2D (57) is an analytical code based on closed-form solutions of the non-conservative solute transport equation for instantaneous and continuous releases of a tracer in one or more source locations as presented by Wilson and Miller (58). The program uses superposition of solutions for individual sources to calculate the resulting concentration distribution for a tracer in a homogeneous, confined aquifer with uniform regional flow. The code evaluates the effects of solute advection and dispersion in an aquifer with multiple (up to 25 ) fully penetrating sources. It is limited to retardation and first-order decay for a single species.

Interactive Models for Groundwater Flow and Solute Transport

Valocci et al. (59) developed Java code for interactive modeling of flow and reactive transport in one, two, and three dimensions. This code covers solutions for single species transport. Using any Internet web browser, analytical modeling can be conducted remotely using this application.

\section{Numerical Computer Codes for Biodegradation and Reactive Transport}

Several numerical computer codes have been developed to model biodegradation and reactive transport. The limited review to follow considers only those frequently used in the environmental industry. 
NUFT

The NUFT code (37) is a numerical suite for modeling multiphase, multicomponent reactive transport under non-isothermal conditions. It simulates advection, dispersion, reactions (both kinetics and equilibria), thermal conduction, and radiation, etc. in multiple overlapped porous and non-porous media. It has been successfully used in modeling of bioventing and steam injection for groundwater remediation (47) and of hydrothermal behavior at nuclear disposal sites. Finite element and finite difference solution options, together with internal structured, external nonstructured, and multigrid meshes, are available.

\section{TOUGHREACT}

The TOUGHREACT code (40) was developed based on TOUGH2 for multiphase and multicomponent reactive transport. A variety of equilibrium reactions are covered, such as aqueous complexation, as dissolution/exsolution, mineral dissolution/precipitation, and cation exchange. TOUGHREACT has been successfully used for modeling hydrothermal and geochemical systems at nuclear disposal sites and for $\mathrm{CO}_{2}$ disposal in deep aquifers.

$R T 3 D$

The RT3D code (35) is a MODFLOW family code and was developed specifically for modeling bioremediation and reactive transport in a single phase. Since LSODE was implemented for solving a wide range of ODEs, it solves reactive transport with stiff kinetics.

BIOPLUME

The BIOPLUME codes $(60)$ were developed for simulating transport of a single and multiple hydrocarbons in two dimensions with oxygen-limited and reactant-limited bioreactions.

Many other numerical codes for modeling biodegradation and reactive transport are reviewed by Wiedemeier et al. (2) and Rifai and Rittaler (1).

\section{Analytical and Numerical Solutions, an Example and Comparison}

As a demonstration of the differences and similarities of analytical and numerical modeling of reactive transport and biodegradation, we illustrate with an example that is tractable analytically. Consider the one-dimensional reactive transport system of Sun and Clement (15). A reaction branch of the reaction 
network ((15), Figure 1) is used here as a sequential reactive transport problem as for given reaction rates, $\mathbf{k}=\left[\begin{array}{llll}k_{l} & k_{2} & \ldots & k_{5}\end{array}\right]^{T}=\left[\begin{array}{llllll}0.05 & 0.03 & 0.01 & 0.005 & 0.002\end{array}\right]^{T}$ :

$$
\begin{aligned}
& \begin{array}{lllll}
k_{1} & k_{2} & k_{3} & k_{4} & k_{5}
\end{array} \\
& C_{1} \rightarrow C_{2} \rightarrow C_{3} \rightarrow C_{4} \rightarrow C_{5} \rightarrow
\end{aligned}
$$

Both analytical (19) and numerical (35) solutions were computed for a column of $500 \mathrm{~m}$ discretized using 50 evenly spaced nodal points. A uniform groundwater transport velocity of $0.5 \mathrm{~m} / \mathrm{d}$ and dispersion coefficient of $5.0 \mathrm{~m}^{2} / \mathrm{d}$ were assumed. Initial conditions for all species were assumed to be zero.

The boundary conditions assumed are similar to those used in deriving the basic analytical solution (6),

$$
a_{i}=\frac{a_{i}^{o}}{2} \exp \left(\frac{v x}{2 D}\right)\left[\exp \left(-B_{i} x\right) \operatorname{erfc} \gamma_{i}^{-}+\exp \left(B_{i} x\right) \operatorname{erfc} \gamma_{i}^{+}\right]
$$

where

$$
\begin{aligned}
& B_{i}=\left(\frac{v^{2}}{4 D^{2}}+\frac{k_{i}}{D}\right)^{1 / 2}, \quad \operatorname{erfc}(\eta)=1-\operatorname{erf}(\eta)=\frac{2}{\sqrt{\pi}} \int_{\eta}^{\infty} \exp \left(-\tau^{2}\right) d \tau \\
& \gamma_{i}^{-}=\frac{x-\left(v+4 k_{i} D\right)^{1 / 2} t}{2(D t)^{1 / 2}}, \quad \gamma_{i}^{+}=\frac{x+\left(v+4 k_{i} D\right)^{1 / 2} t}{2(D t)^{1 / 2}}
\end{aligned}
$$

Using eq 3 or eq 5 , the transformation matrices are obtained:

$$
\mathbf{S}=\left[\begin{array}{ccccc}
1 & 0 & 0 & 0 & 0 \\
\frac{k_{1}}{k_{2}-k_{1}} & 1 & 0 & 0 & 0 \\
\prod_{l=2}^{3} \frac{k_{l-1}}{k_{l}-k_{1}} & \frac{k_{2}}{k_{3}-k_{2}} & 1 & 0 & 0 \\
\prod_{l=2}^{4} \frac{k_{l-1}}{k_{l}-k_{1}} & \prod_{l=3}^{4} \frac{k_{l-1}}{k_{l}-k_{2}} & \frac{k_{3}}{k_{4}-k_{3}} & 1 & 0 \\
\prod_{l=2}^{5} \frac{k_{l-1}}{k_{l}-k_{1}} & \prod_{l=3}^{5} \frac{k_{l-1}}{k_{l}-k_{2}} & \prod_{l=4}^{5} \frac{k_{l-1}}{k_{l}-k_{3}} & \frac{k_{4}}{k_{5}-k_{4}} & 1
\end{array}\right]
$$




$$
\mathbf{S}^{-1}=\left[\begin{array}{ccccc}
1 & 0 & 0 & 0 & 0 \\
\frac{k_{1}}{k_{1}-k_{2}} & 1 & 0 & 0 & 0 \\
\prod_{l=1}^{2} \frac{k_{l}}{k_{l}-k_{3}} & \frac{k_{2}}{k_{2}-k_{3}} & 1 & 0 & 0 \\
\prod_{l=1}^{3} \frac{k_{l}}{k_{l}-k_{4}} & \prod_{l=2}^{3} \frac{k_{l}}{k_{l}-k_{4}} & \frac{k_{3}}{k_{3}-k_{4}} & 1 & 0 \\
\prod_{l=1}^{4} \frac{k_{l}}{k_{l}-k_{5}} & \prod_{l=2}^{4} \frac{k_{l}}{k_{l}-k_{5}} & \prod_{l=3}^{4} \frac{k_{l}}{k_{l}-k_{5}} & \frac{k_{4}}{k_{4}-k_{5}} & 1
\end{array}\right]
$$

A constant concentration condition $\left(c_{1}^{o}=1.0, c_{i}^{o}=0, \forall i>1\right)$ is set at the inlet and a free boundary condition is assumed at the outlet boundary. Note that all yield coefficients $y_{i}=1, \forall i$ are assumed in this example. Concentration profiles are compared in Figure 3 when $t=730 \mathrm{~d}$. The CPU time ratio between analytical solution and numerical solution is usually very small (in this 5-species case the ratio was 0.116 between the analytic solution CPU and the RT3D solution CPU). This specific example illustrates both the faster run time and the mathematical transparency of the analytical solution in contrast to the numerical solution.

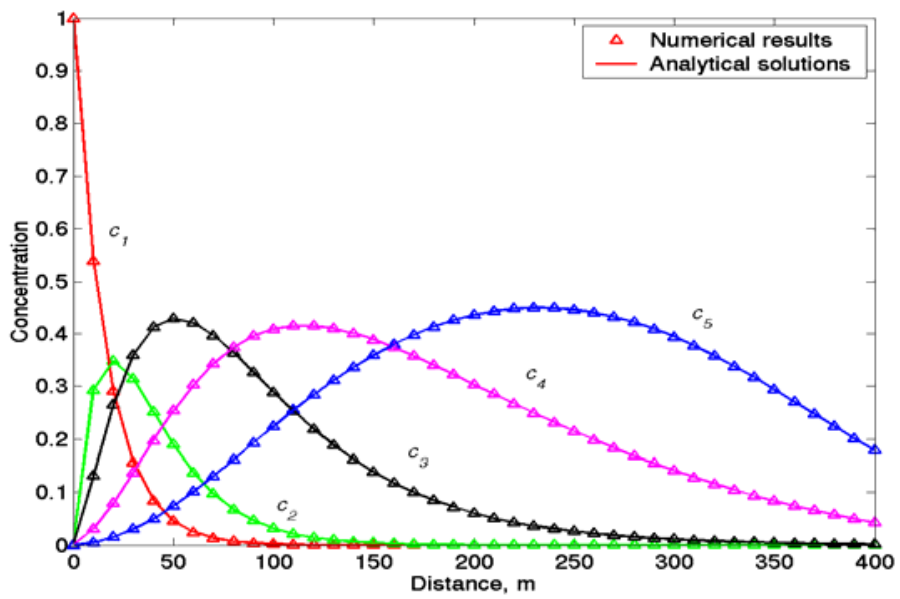

Figure 3. Concentration profiles of five species after two years .

In addition, since analytical solutions can be expressed in a functional format, they can be easily used for system identification (as inverse problems, $(12,61$, $62)$ ), sensitivity analyses (8), and numerical code verification $(15,63,64)$. 
However, numerical solutions are much closer to the real world systems and are never limited to the assumptions that are used to derive analytical solutions.

\section{Conclusions and Future Considerations}

In this chapter, analytical and numerical approaches to modeling reactive transport and bioremediation were reviewed, and the tradeoffs and benefits of both approaches were discussed. Because of their relative ease of use and speed in providing insight into biodegradation processes, analytical solutions play an important role in modeling bioremediation and natural attenuation at the screening and planning stages. However, when initial conditions, boundary conditions, and/or reaction kinetics require high-resolution, numerical models are often the best solution. For high-resolution modeling at late stages, analytical models can be used for numerical code verification and conceptual model validation. In all cases, numerical and analytical models should be viewed as complementary tools, providing the planner and researcher with a dualcapability of making both rapid and detailed analysis of biodegradation and reactive transport systems.

A number of improvements to modeling of reactive transport are possible. It has been realized that the lack of the closed form analytical solution of sequentially reactive transport with different retardation factors has limited the application of analytical codes, such as BIOCHLOR (55). To sufficiently apply analytical solutions in real world systems, the conformal transformation is a promising direction for converting heterogeneous and anisotropic systems into uniform flow systems. Web-based simulation, especially for analytical solutions, has great potential. On the numerical side, it would be beneficial to develop a model translator, which can convert database information to model input files and convert model input files between different computer codes. Users may then benefit from the ability to select the most appropriate computer code and adjust (or easily update) the model input.

\section{Acknowledgements}

This work was performed under the auspices of the U. S. Department of Energy by the University of California, Lawrence Livermore National Laboratory under Contract No. W-7405-Eng-48. 


\section{References}

1. Rifai, H.S.; Rittaler, T. Biodegradation. 2005, 16, 291-304.

2. Wiedemeier, T.H.; Rifai, H.S.; Newell, C.J.; Wilson, J.W. Natural attenuation of fuels and chlorinated solvents; John Wiley \& Sons, Inc.: New York, 1999.

3. Wiedemeier, T.H.; Swanson, M.A.; Moutoux, D.E.; Gordon, E.K.; Wilson, J.T.; Wilson, B.H.; Kampbel, D.H.; Hansen, J.; Haas, P.; Chapelle, F.H. Technical protocol for evaluating natural attenuation of chlorinated solvents in groundwater; Air Force Center for Environmental Excellence, Technology Transfer Division, Brooks AFB: San Antonio, TX, 1996.

4. Semprini, L.; Roberts, P. V.; Hopkins, G. D.; McCarty, P. L. Ground Water. 1990, 28, 715-727.

5. Sun, Y.; Lu, X.; Petersen, J.N.; Buscheck, T.A. Transport Porous Med. 2004, 55, 301-308.

6. Bear, J. Groundwater hydraulics; McGraw-Hill: New York, 1979.

7. Javandel, I.; Doughty, C.; Tsang, C.F. Groundwater Transport, American Geographical Union, Washington, D.C., 1984.

8. Lu, X.; Sun, Y.; Petersen, J.N. Transport Porous Med. 2003, 51, 211-225.

9. Ogata, A. Ph.D. thesis, Northwestern University, Evanston, IL, 1958.

10. Bear, J. Ph.D. thesis, University of California, Berkeley, CA, 1960.

11. van Genuchten, M.Th.; Alves, W.J. Analytical solutions of the onedimensional convective-dispersive solute equation; Agricultural Research Service, Department of Agriculture: Riverside, CA, 1982.

12. Toride, N.; Leij, F.J.; van Genuchten, M.Th. The CXTFIT code for estimating transport parameters from laboratory and field tracer experiments; U.S. Salinity Laboratory Report: No. 137, 1995.

13. Beljin, M.S. Review of three-dimensional analytical models for solute transport in groundwater system; International Ground Water Modeling Center: Holcomb Research Institute, Butler University, Indianapolis, IN, 1991.

14. Wexler, E.J., Analytical solutions for one-, two-, and three-dimensional solute transport in ground-water systems with uniform flow; U. S. Geol. Survey: Book 3, Ch. B7: Denver, CO, 1992; p199.

15. Sun, Y.; Clement, T.P. Transport Porous Med. 1999, 37, 327-346.

16. Cho, C.M. Can. J. Soil Sci. 1970, 51, 339-350.

17. Lunn, M.; Lunn, R.J.; Mackay, R. J. Hydrology. 1996, 180, 195-210.

18. van Genuchten, M.Th. Comput. Geosci. 1985, 11, 129-147.

19. Sun, Y.; Petersen, J.N.; Clement, T.P.; Skeen, R.S. Water Resour. Res. 1999, 35, 185-190.

20. Sun, Y.; Petersen, J.N.; Buscheck, T.A.; Nitao, J.J. Transport Porous Med. 2002, 49, 175-190.

21. Clement, T.P. Water Resour. Res. 2001, 37, 157-163. 
22. Eykholt, G.R.; Li, L. J. Contam. Hydrol. 2000, 46, 163-185.

23. Bauer, P.; Attinger, S.; Kinzelbach, W. J. Contam. Hydrol. 2001, 49, 217-239.

24. Quezada C.R.; Clement, T.P.; Lee, K.K. Adv. Water Resour. 2004, 27, 508-521.

25. Nitao, J.J.; Buscheck, T.A. Water Resour. Res. 1991, 27, 2099-2112.

26. Berkowitz, B.; Zhou, J. Water Resour. Res. 1996, 32, 901-913.

27. Tang, D.H.; Frind, E.O.; Sudicky, E.A. Water Resour. Res. 1981, 17, 555-564.

28. Sudicky, E.A.; Frind, E.O. Water Resour. Res. 1982, 18, 1634-1642.

29. Sudicky, E.A.; Frind, E.O. Water Resour. Res. 1984, 20, 1021-1029.

30. Cormenzana, J. Water Resour. Res. 2000, 36, 1339-1346.

31. Sun, Y.; Buscheck, T.A. J. Contam. Hydrol. 2003, 62-63, 695-712.

32. Sun, Y.; Clement, T.P.; Petersen, J.N.; Hooker, B.S. A modular computer model for simulating natural attenuation of chlorinated organics in saturated groundwater aquifers, Environmental Monitoring Tools Conference, Annapolis, MD, December, 1996.

33. Sun, Y.; Petersen, J.N.; Clement, T.P.; Hooker, B.S. J. Contam. Hydrol. 1998, 31, 147-162.

34. Rifai, S.H.; Bedient, P.B. Water Resour. Res. 1990, 26, 637-645.

35. Clement, T.P.; Sun, Y.; Hooker, B.S.; Petersen, J.N. Ground Water Monit. Remediat. 1998, 18, 79-92.

36. Clement, T.P.; Johnson, C.D.; Sun, Y.; Klecka, G.M.; Bartlett, C. J. Contam. Hydrol. 2000, 42, 113-140.

37. Nitao, J.J. Reference Manual for the NUFT Flow and Transport Code, Version 2.0; Lawrence Livermore National Laboratory: UCRL-MA$130651,1998$.

38. Glascoe, L.G.; Wright, S.J.; Abriola, L.M. J. Environ. Eng. 1999, 125, 1093-1102.

39. Sun, N. Water Resour. Res. 2002, 38, 1029, 10.1029/2000 WR000198.

40. Xu, T.; Sonnenthal, E.L.; Spycher, N.; Pruess, K. TOUGHREACT user's guide A simulation program for non-isothermal multiphase reactive geochemical transport in variable saturated geologic media; Lawrence Berkeley National Laboratory Report: LBNL-55460, Berkeley, CA, 2004.

41. Zheng, C.; Wang, P.P. MT3DMS: A modular three-dimensional multispecies transport model for simulation of advection, dispersion, and chemical reactions of contaminants in groundwater systems; US Army Engineer Research and Development Center: SERDP-99-1, Vicksburg, MS, 1999.

42. Bateman, H. Proc. Cambridge Phyil. Soc. 1910, 15, 423.

43. Borden, R.C.; Bedient, P.B. Water Resour. Res. 1986, 22, 1973-1982.

44. Molz, F.J.; Widdowson, M.A.; Benefield, L.D. Water Resour. Res. 1986, $22,1207-1216$. 
45. Kinzelback, W.; Schafer, W.; Herzer, J. Water Resour. Res. 1991, 27, $1123-1135$.

46. Cirpka, O.A.; Frind, E.O.; Helmig, R. J. Contam. Hydrol. 1999, 40, 159-182.

47. Sun, Y.; Demir, Z.; Delorenzo, T.; Nitao, J.J. Application of the NUFT code for subsurface remediation by bioventing; Lawrence Livermore National Laboratory: UCRL-ID-137967, CA, 2000.

48. Waddill, D.W.; Widdowson, M.A. J. Environ. Eng. 1998, 124, 336-344.

49. Dortch, M.S.; McGrath, C.J.; Nitao, J.J.; Widdowson, M.A.; Yabusaki, S. Development of simulators for in situ remediation evaluation, design, and operation: Final report; U.S. Army Corps of Engineers: ERDC/EL TR01033, 2001.

50. Radhakrishnan, K.; Hindmarsh, A.C. Description and use of LSODE, the Livermore $=$ solver for ordinary differential equations; Lawrence Livermore National Laboratory: report UCRL-ID-113855, Livermore, CA, 1993.

51. Gear, C.W. The automatic integration of ordinary differential equations, Morrell, A.J.H., ed., Information Processing; North-Holland Publishing Co.: New York, 1969; 187-193.

52. MathWorks MATLAB high-performance numeric computation and visualization software; Web site: www.mathwroks.com: Natick, MA, 2000.

53. Yeh, G.T. AT123D: Analytical transient one-, two-, and three-dimensional simulation of waste transport in the aquifer system; Oak Ridge National Laboratory: ORNL-5602, 1981; p88.

54. Domenico, P.A. J. Hydrology. 1987, 91, 49-58.

55. Aziz, C.E.; Newell, C.J.; Gonzales, G.R.; Haas, P.E.; Clement, T.P.; Sun, Y. BIOCHLOR-Natural attenuation decision support system, Beta version 1.0, User's Manual; Subsurface Protection and Remediation Division, National Risk Management Research Laboratory: Ada, OK, 74820, 1999.

56. Clement T.P.; Truex, M.J.; Lee, P. J. Contam. Hydrol. 2002, 59, 133-162.

57. van der Heijde, PLUME2D, www.mines.edu/igwme/software/.

58. Wilson, J.L.; Miller, P.J. J. Hydraul. Div. 1978, 104, 503-514.

59. Valocci, A.J.; Werth, C.J.; Decker, J.J.; Hammond, G.; Zhou, P. Interactive model for groundwater flow and solute transport; University of Illinois: 2003, www.cee.uiuc.edu/transport/.

60. Rifai, H.S.; Newell, C.J.; Gonzales, J.R.; Dendrou, S.; Kennedy, L.; Wilson, J. BIOPLUME III Natural attenuation decision support system version 1.0 User's Manual; Brooks Air Force Base: San Antonio, TX, 1997.

61. Buscheck, T.E.; Alcantar, C.M. Regression techniques and analytical solution to demonstrate intrinsic bioremediation, In R.E. Hinchee et al., ed. Intrinsic Bioremediation; 109-116, Battelle Press: Columbus, OH, 1995.

62. Sun, Y.; Bear, J.; Petersen, J.N. J. Contam. Hydrol. 2001, 51, 83-95.

63. Zhang, K.; Woodbury, A.D. Adv. Water Resour. 2002, 25, 705-721. 
UCRL-JRNL-212942

64. Zhang, G.X.; Zheng, Z.P.; Wan, J.M. Water Resour. Res. 2005, 41, W02018. 